This effect of parathyroid hormone on hydrogen ion gradient presumably accounts for the metabolic acidosis in patients with primary hyperparathyroidism.

Similarly, the low plasma chloride found in patients with hypercalcaemia from other causes may be due to renal tubular alkalosis and it is relevant that G. Richet and colleagues $^{7}$ found a rapid fall in urinary $\mathrm{pH}$ in 16 adults given calcium by intravenous iniection. Furthermore, a metabolic alkalosis has been detected in patients with hypoparathyroidism, where the absence of parathyroid hormone may lead to failure of tubular reabsorption of hydrogen ions. Patients with hypercalcaemia from causes other than hyperparathyroidism presumably have the secretion of their parathyroid hormone suppressed, this contributing to the metabolic alkalosis and low plasma chloride.

It has been realized for several years that a variety of tumours, either carcinomata or sarcomata, may produce the clinical picture of hyperparathyroidism. ${ }^{8}$ Immunological studies suggest that a polypeptide similar to parathyroid hormone is produced, though its chemical structure has not been elucidated. Five patients with this syndrome had a metabolic alkalosis and a plasma chloride below $102 \mathrm{mEq} /$ litre in contrast to patients with primary hyperparathyroidism described above. ${ }^{5}$ On this evidence it would appear that the biological activity of the hormone produced by the tumour differs from that of parathyroid hormone.

Many biochemical tests have been proposed to distinguish the hypercalcaemia of primary hyperparathyroidism from other causes of hypercalcaemia. Cortisone suppression tests and indices of phosphate excretion by the kidney each have their advocates. The simple but accurate measurement of plasma chloride levels, together with an assessment of the patient's acid-base status, would appear to be worth studying as a diagnostic procedure.

Wills, M. R., and McGowan, G. K., British Medical Fournal, 1964, 1, 1153. Thomas, W. C., Connor, T. B., and Morgan, H. G., fournal of Laboratory and Clinical Medicine, 1958, 52, 11.

3 Howard, J. E., Transactions and Studies of the College of Physicians of Philadelphia, 1962, 52, 11 .

4 Pyrah, L. N., Hodgkinson, A., and Anderson, C. K., British fournal of Surgery, 1966, 53, 245.

5 Wills, M. R., fournal of Clinical Pathology, 1971, 24, 219.

- Nordin, B. E. C., Clinical Science, 1960, 19, 311.

7 Richet, G., Ardaillou, R., Amiel, C., and Lecestre, M., fournal d'Urologie

et de Nephrologie, 1963, 69, 373.
Fry, L., British Medical fournal, 1962, 1, 301.

\section{Prognosis in Industrial Dermatitis}

Accurate information about the prognosis for workers with industrial dermatitis is scanty. In $1958 \mathrm{~F}$. F. Hellier ${ }^{1}$ reported his findings on 124 patients with industrial dermatitis four or more years after he had examined them for a legal report, and recently $M$. L. Johnson and $H$. T. $H$. Wilson ${ }^{2}$ have followed up 87 out of 100 workers with oil dermatitis whom they had seen for a similar reason. Both these groups of patients were selected from the more severe and persistent sufferers and may not represent the true picture as seen by the works doctor in the factory. It is difficult to see how all mild cases could be followed up for any time owing to the constant movement of labour. Johnson and Wilson divide their patients into six groups, among which are those with oil dermatitis, oil dermatitis with constitutional eczema, constitutional eczema, and oil folliculitis. The points in favour of a true oil dermatitis were absence of a history of previous skin trouble, contact with oil, the distribution of the rash on exposed areas, improvement on removal from the work, and relapse on re-exposure. Even with these criteria it is clear that if 20 men are doing the same job and only one gets dermatitis he must to some extent be predisposed to it. A major problem in assessing such cases at a tribunal is to determine the relative importance of the internal and external factors. The authors appreciate this by placing ten cases in the mixed group; 17 of their patients had purely constitutional eczema. They state, correctly, that a rash should not be considered constitutional merely because of its patchy distribution if it is otherwise acceptable as dermatitis. Experience has shown that a true exogenic dermatitis, particularly of some standing, may take on a constitutional pattern, and that an accurate history is just as important as how the rash is distributed. Oil folliculitis is a much less disabling condition than true oil dermatitis and affected only four of the men they examined. But an inspection of workers in the factory would show that it is common, though it does not prevent them from continuing to work in contact with oil.

The term oil covers a wide range of substances from heavy lubricating oils to soluble oils with their various additives, but Johnson and Wilson did not find any differences in their effects on the prognosis and so have included them in one group. Nor did they distinguish between dermatitis due to the primary irritant effect of oil and true sensitization. However, this can influence the prognosis. Hellier showed that in sensitization dermatitis removal from the offending irritant was followed by clearance of the rash in $32 \%$ of his cases, whereas when the outbreak was due to a primary irritant only $14 \%$ escaped further trouble. Johnson and Wilson found that of 46 patients with oil dermatitis who changed their job 26 $(57 \%)$ lost the rash, but in 5 out of 6 patients with only mild disease the rash cleared up while they continued at work. This may be explained by the fact that many workers develop a mild rash soon after starting work, but it disappears as the skin becomes "hardened." Alternatively, they may have taken precautionary measures to cut down the exposure, a point made by Hellier in discussing dermatitis due to primary irritants, when he suggested that such men should be encouraged to continue at work with their old firm with suitable precautions rather than try to find work elsewhere. Johnson and Wilson found that the chance of ultimate recovery was less in those who continued at work for over a year with the rash than for those exposed for a shorter time. Those cases diagnosed as constitutional eczema had the worst prognosis, as might be expected, whether they changed their job or not.

It has usually been considered that the prognosis is worse in older workers than younger, but Johnson and Wilson could not confirm this, though their figures are admittedly rather small. They also found that the payment or not of "compensation," which it is assumed includes injury benefit, did not affect the prognosis. Possibly it is delay in the settlement of a claim rather than the actual decision which is important, though this was not shown in the small numbers with which they dealt.

${ }^{1}$ Hellier, F. F., British Medical fournal, 1958, 1, 196

2 Johnson, M.' L., and Wilson, H. T. H., British fournal of Industrial Medicine, 1971, 28, 122. 